Psychology of Language and Communication 2011, Vol. 15, No. 1

VERSITAOPEN

DOI: $10.2478 / \mathrm{v} 10057-011-0005-1$

\author{
DOROTA KUNCEWICZ
}

Academy of Special Education, Warsaw

\title{
CONFLICT RESOLUTION AND RELATIONAL PATTERNS IN THE FAMILIES OF ORIGIN OF WOMEN AND MEN
}

\begin{abstract}
The aim of the studies was to seek an answer to the following question: Which relationship patterns correlate with different conflict resolution strategies in women's and men's intimate relationships? The subjects were 56 engaged couples (aged 19-37) answering Conflict Resolution Strategy Questionnaires, Personal Authority in the Family System Questionnaires and The Family of Origin Scale. The network of correlations between conflict resolution strategies and relationship patterns is more complex for women than for men. In the women's group, the correlation connects constructive strategies (dialogue and loyalty) foremost with patterns defining intimacy (or its components). However, destructive strategies (exit and neglect) are related to patterns definitive of individuation levels in the family of origin, independence and position. In the men's group, however, the correlation connects conflict resolution strategies (constructive and destructive) to relationship patterns definitive of partner relations. Furthermore, constructive strategies are associated with lower intergeneration triangulation intensity and higher intergenerational intimidation intensity.
\end{abstract}

Key words: conflict resolution, relationship patterns, difference between the sexes

\section{Introduction}

Many researchers (including Edwards, Allen, \& Hayhoe, 2007; Reese-Weber \& Kahn, 2005; Reese-Weber \& Bartle-Haring, 1998; Simon \& Furman, 2010; Darling, Cohan, Burns, \& Thompson, 2008) have connected the issue of gender differences and their relationship to experiences in the family of origin in the context of conflict resolution. This study concerns a topic which up to this time has received little attention - the differences (arising from gender) in the relationship between conflict resolution strategies and relational patterns. Are the same or different relational patterns linked to certain conflict resolution strategies in women and men? Do men and women differ in their perceptions of relational patterns and preferred

Address for correspondence: Dorota Kuncewicz, Academy of Special Education, Institute of Applied Psychology, Szczęśliwicka 40, 02-353 Warszawa, Poland. E-mail: dkuncewicz@aps.edu.pl 
Figure 1. Typology of conflict resolution strategies in close relationships (Rusbult, Johnson, \& Morrow, 1986, p. 745)

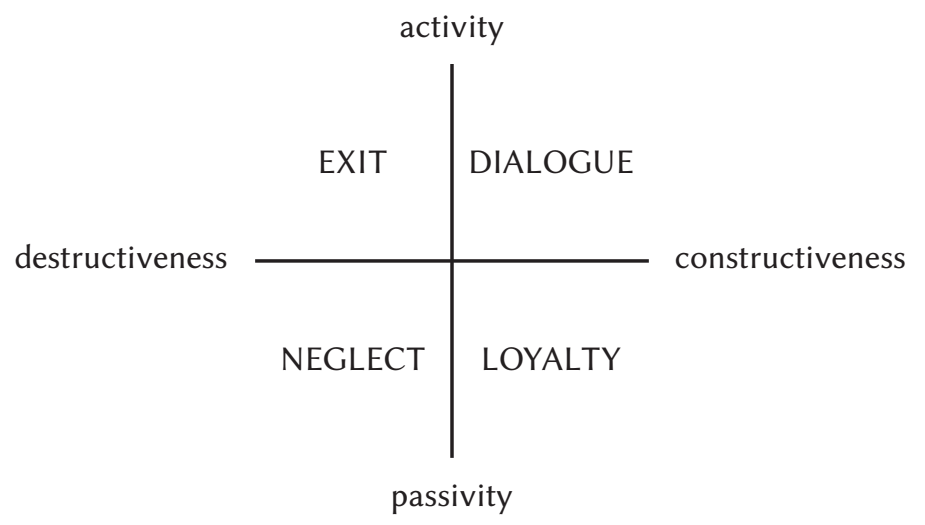

strategies, or only on the level of the relation between these variables? It may be that the perception of intensification of relational patterns is similar, but the degree of gender dependence is different. Perhaps the intensification of some relational patterns is of greater significance for conflict resolution strategies of women and the intensification of other patterns is more significant for strategies preferred by men. The subjects were asked to fill in three questionnaires. In one questionnaire, the frequency of their behavior in conflict situations was estimated, which consisted of specific conflict resolution strategies. In the two other questionnaires, the subjects specified the current relational patterns in their families of origin and current partner relationship.

\section{Conflict resolution strategies}

The Rusbult concept is simple (without over-simplification) and useful: reactions to dissatisfaction and/or conflict in a relationship are classified according to two basic dimensions: constructiveness-destructiveness (from the perspective of the relationship) and activeness-passiveness (Figure 1). The interaction of these two dimensions allows four types of behavior to be distinguished. The two constructive problem-solving strategies in the relationship are active dialogue and passive loyalty, and the two destructive strategies are active exit and passive neglect (Rusbult, Zembrodt, \& Gunn, 1982; Rusbult, Johnson, \& Morrow, 1986).

Dialogue. This is understood as making attempts to eliminate the problem and maintain relations in good order.

Loyalty. This strategy (passive and constructive) means patiently waiting out the problem in the hope that it will resolve itself. Adaptation to the partner's 
expectations, or mitigation of the situation (which may lead to conflict) is applied when behavior of compliance and avoiding open confrontation is more important than satisfying one's own needs.

Exit. This strategy is understood as the active destruction of the relationship through neglect and is therefore an attack on a partner, persisting until separation or divorce. The partners aspire to resolve the conflict - each on their own terms, without considering the needs of the other. Both sides try to exert pressure, use threats, punishments, undermine the needs and goals of the partner, at the same time putting forth increasingly excessive demands in order to compel the other partner to step down.

Neglect. This is a strategy in which one partner withdraws from contact with the other, from discussing the problem or conversing with them altogether. Taking no action towards solving the problem is related to lack of faith in the possibility of restoring mutual relations.

\section{Relational Patterns}

Relational patterns here are understood to be in accordance with the definition proposed by Fajkowska-Stanik (2001, p. 77), and these are "relatively permanent systems of emotional references between individuals in a family, reflected in concrete, sequential behaviors and reinforced through mechanisms of social learning, modeling, identification, projection, and are built by expectations, principles, commitments and personality features of family members, passed on from generation to generation and recurring in various conditions (e.g. in relationships within a family formed by the younger generation)."

Autonomy is shaped in large part on the basis of family relations, and is the result of a conscious resigning from an overly intense (characteristic for small children) attachment to parents. This is a choice for greater autonomy, while concurrently maintaining bonds (Fajkowska-Stanik, 2001, p. 86). By a similar token, Bowen (1978) uses the term individuation, with which he defines the level of autonomy and independence of individuals in the group, in both the emotional and intellectual spheres.

Intimacy in the mature form is no longer based on a child's dependency on a parent, but on equal-partner relationships. The process of self-distinguishment and defining the increasing area of autonomy by this time allows adult family members to redefine the intimacy that binds them. This is already a relationship of autonomous individuals who have earned themselves their own identities, respect and understanding. This is intimacy entailing the respecting of borders.

Personal authority in the family system means the position which an individual assumes in the family. For an adult child, the parent loses a higher position in the hierarchy to the equal-partner relationship. The adult child experiences and relates to everyone without exception, including parents, as equal partners. 
Fusion is a state of extreme attachment in the family system. The family functions on the assumption that genuine meeting of emotional needs and sense of security is possible exclusively in the family system. The outside world is threatening and causes anxiety.

Triangulation. In a conflict-escalating situation, the couple may face a dilemma - if one wins and the other loses, will their relationship cease to exist? (Bowen, 1976, p. 75-76). Rising tension may be neutralized and the pair's conflict may become less apparent (Scarf, 1989, p. 56) through incorporating a third person into the relationship. This may be a family member or a person from another system. Two primary ways of incorporating a third person into a relationship in turmoil can be distinguished:

1. One of the partners changes the balance in the dyad, forming an alliance with a third person (Minuchin, 1974, p. 102).

2. The partners may also avoid conflict by making problems out of the third person. They may do so through attack or support (Hoffman, 1981, p. 68). In the first case, they accuse the triangulated person of being the source of the problems; a common enemy unites them. In the second option, however, they seek out or exaggerate the problems of one of the family members - assigning them the role of the sick or weak (usually a child, but it could also be a parent of one of the partners), thanks to which rather than resolving the conflict, they can unite in the care and protection of the third person (Minuchin, 1974, p. 102). In a way, the triangulated person is delegated to providing problems (Stierlin, et al. 1980). The couple does not have to confront their own problems, emotions or frustrations.

Intergenerational intimidation is a pattern based on low autonomy, hierarchical boundaries and lack of mature intimacy. Dependence is associated with anxiety that the parents will withdraw their support, without which the individual cannot cope.

\section{Hypotheses}

It is predicted that:

1. Men and women differ in conflict resolution strategies.

Women prefer active conflict resolution strategies (dialogue, exit), whereas men prefer passive strategies (loyalty, neglect). Among other things, these differences may result from different communication strategies, different degrees of involvement in family relationships, a stronger focus on relationships with other people. Men's communication in close relationships (in conflict situations) is characterized by an emotional winning over, while women's communication is characterized by attack and rejection (Raush, Barry, Hertel, \& Swain, 1974) Moreover, women tend to initiate conflict resolution, which may result from their relatively stronger participation in relationships. 
2. Men and women do not differ in perceptions of relational patterns.

The essential similarity of the socialization processes of girls and boys is asserted only with reference to certain socialization activities - feelings revealed toward the child or type of interaction (Maccoby \& Jacklin 1974; Margonin \& Patterson 1975). On the basis of meta-analysis of 172 studies, Lytton and Romney (1991) likewise have shown that in this respect, the sex of the child does not have a significant impact on the socialization process in the family (beyond a tendency to express greater affection to girls).

3. A similar perception of the intensity of relational patterns will create other relationships among women and men, correlated with their conflict resolution strategies.

According to studies conducted by Bell, Cowan and Cowan (1995), women first indicate the problem to be resolved, however the decision as to which solution will ultimately be decided upon belongs more to the man. An equal influence on the course of the discussion carries more importance for women. They feel greater satisfaction from the course of discussions and the relationship. While simultaneously taking into consideration the numerous studies indicating the importance of intimacy for women, the following detailed hypotheses may be formulated:

3a. Higher levels of intergenerational and partnership intimacy and personal authority among women coincide with constructive strategies, whereas lower levels of both intergenerational and partnership intimacy and lower levels of personal authority among women coincide with destructive strategies.

3 b. Constructive conflict resolution strategies among men are mainly associated with higher levels of autonomy, with lower levels of autonomy being conducive to destructive strategies.

\section{Research method}

\section{The subjects}

Couples were chosen for the study, thanks to which the men and women do not differ significantly in the intensity and quality of the conflicts in the objective dimension (they may, of course, differ subjectively in the perception of even the same conflict).

A total of 148 people were surveyed, of which 36 were rejected for providing incomplete questionnaires, so that 112 people (56 pairs) qualified for the final analysis.

All the couples were in the course of wedding preparations after deciding to get married (most of them had an exact date set and reserved for the wedding), which was taken as an indicator of a similar stage of relationship development regardless of the length of its duration.

The subjects ranged from 19 to 37 years of age. Due to method limitations, the study only included people with a secondary (48\%) and higher (52\%) education. 
The duration of the relationships ranged from one to seven years. Less than $30 \%$ of couples declared joint residence. Joint/separate residence did not differentiate the pairs in the scope of the research variables. All the subjects participated in the study voluntarily and received no compensation.

\section{Research tools}

Three research methods were applied in this study, presented below. The first method allows the dependent variable of conflict resolution strategies to be characterized, while the others describe the independent variables of relational patterns.

The Conflict Resolution Strategy questionnaire was constructed by Kriegelewicz (2003), based on the "Problem Solving Patterns" questionnaire authored by Rusbult, Johnson and Morrow (1986). The questionnaire comprises 32 items that make up four scales: dialogue, loyalty, exit and neglect. Each scale consists of 8 items.

1. Dialogue includes discussions on the problem, searching for compromise and solutions, trying to understand the partner well, openness in disclosing thoughts and feelings concerning problematic issues and the ability to apologize. Example item: "Even during an argument, I try to familiarize myself with and understand my partner's point of view."

2. Loyalty is associated with faith in the partner's good intentions, tolerating their flaws, hope for "better times" in the relationship and faith that the relationship with the partner will survive, despite arising difficulties and problems. Example item: "If my partner upsets me, I try to justify his actions."

3. Exit, meaning criticizing, evaluating and accusing the partner, verbal aggression and exploiting weakness. Example item: "When my partner irritates me, I pull no punches."

4. Neglect manifests itself in ignoring the partner, limiting the time spent with them, denial of discussions, cold treatment of the partner, not discussing disputed issues and isolation. Example item: "When my partner's behavior angers me, I stop talking to him."

The tests provide answers on a six-degree scale of the frequency with which certain behaviors towards a partner manifest themselves in conflict situations. Each item is scored on a 0 to 5 scale. The sum of points for a given scale is divided by the number of items, so that results within each scale may be up to 5 points. The higher the score of a given scale, the more often the subject ascribes the application of a certain strategy in a conflict with their partner. Satisfactory reliability (dialogue: $\alpha$ $=0.88$; loyalty: $\alpha=0.82$; exit: $\alpha=0.87$; neglect: $\alpha=0.86$ ) and accuracy (content: $\mathrm{W}$ $=0.375, \mathrm{p}<0.0001$; theoretical: $\chi 2=466.064 \mathrm{p}<0.001$ ) obtained in validation studies allows the methods to be applied for research purposes. The reliability coefficients in this study for the given scales came out to be: dialogue: $\alpha=0.87$; loyalty: $\alpha=$ 0.84; exit: $\alpha=0.88$; neglect: $\alpha=0.88$.

The Personal Authority in the Family System Questionnaire. Relational patterns are examined by the Personal Authority in the Family System Question- 
naire concerning the family of origin and partner dyad. The questionnaire has three versions. Version B was utilized in the study described below. The items are rated on a five-degree Likert-type scale. The test items are grouped into seven scales:

1. Partner fusion/individuation - this scale measures the extent to which an individual's relationship with their partner is of a fusional nature, and to what extent both partners retain autonomy in the relationship. Example item: It is not easy for my partner to go to get-togethers without me.

2. Intergenerational fusion/individuation - this scale measures the extent to which an individual's relationship with their parents is of a fusional nature, and to what extent both sides retain autonomy in the relationship. Example item: In the relationship with my parents, emotions are often stirred up in me to the point that I cannot think straight.

3. Partner intimacy - this scale measures the degree of intimacy and satisfaction with the relationship with the partner. Example item: We often talk about important events in our lives. 4. Intergenerational intimacy - this scale measures the degree of intimacy and satisfaction with relationships with parents. Example item: I sometimes get together with my father to chat with him and relax.

5. Intergenerational triangulation - this scale assesses the occurrence of triangulation in the relationship between a given person and their parents. Example item: To what degree do you feel that you are responsible for finding solutions when your parents are experiencing serious marital problems?

6. Intergenerational intimidation - this scale estimates the degree of personal intimidation experienced by an individual in the relationship with their parents, which refers to, among other things, lack of maturity and loss of independence. Example item: How important is it for you to live up to your mother's career expectations?

7. Personal authority - this scale measures the interactive aspects of personal authority, reflecting the topics discussed, which require a certain emotional intimacy with parents in order to be taken up, while at the same time maintaining an appropriate level of individuation. Example item: Do you talk to your parents about their errors and bad decisions?

The various scales are composed of different numbers of questions. Mathematical averages are applied in order to facilitate the comparison of results between the various scales. In all the scales, the results are presented in such a way that a higher score signifies higher intensity of a given pattern.

The psychometric parameters of the method obtained during the adaptation procedure allow it to be regarded as an accurate (content accuracy: $\mathrm{W}=0.97$, $\mathrm{c} 2(131)=378.85, \mathrm{p}<0.001$, theoretical accuracy $\mathrm{a}=0.87$ ) and reliable (reliability coefficient determined by the test-retest method came out to be 0.98 ) tool for measuring relational patterns in the family system. A wider scale and adaptation process is described by Fajkowska-Stanik (1999a). 
The Family of Origin Scale authored by Hovestadt, Anderson, Piercy, Cochran and Fine; translated and adapted by Fajkowska-Stanik (1999b). The questionnaire consists of 10 scales, containing a total of 40 items (four items for each scale). This method is based on the Likert model, where the subject indicates the extent to which a given statement describes their family on a 5-point scale.

The autonomy pattern is described by five scales ( 20 items):

- clarity of expression (each family member is able to express their thoughts and feelings so that they are comprehensible to others without guesswork; example item: "I could easily understand what other family members said and felt"),

- personal responsibility (family members take responsibility for their conduct and can admit to mistakes; example item: "Members of my family often looked for excuses to justify the mistakes they made"),

- respect for other family members (the possibility of expressing different views, beliefs and opinions; example item: "My parents encouraged me to openly express my views"),

- openness to others (acceptance of differences between family members and mutual interest in different perspectives and views on life; example item:"My family accepted that different family members looked at life differently"),

- acceptance of separation and loss (separation and loss is something that the family dealt with; example item:"We talked about the sadness when a friend or family member died").

Another 20 items also describe intimacy on five scales:

- range of feelings (family members may express a wide range of feelings; example item: "In my family, certain feelings were not allowed to be expressed"),

- mood and tone (There was a positive and friendly atmosphere in the family; example item: "I remember my family as warm and supportive"),

- conflict resolution (conflicts are resolved without excessive stress; example item: "Resolving conflicts in my family was a very stressful experience"),

- empathy (family members were sensitive to the matters and feelings of others; example item: "Members of my family were usually sensitive to what others felt"),

- trust (the family assumes that people are inherently good and trustworthy; example item: "In my family I learned to be suspicious of others").

The Family of Origin Scale is an accurate [content accuracy: $W=0.88$; $\mathrm{c} 2(39)=102.8 ; \mathrm{p}<0.001$; theoretical accuracy: $t(25)=10.28 ; \mathrm{p}<0.001 ; \alpha=0.82)]$ and reliable [reliability coefficient 0.96 (SEM=0.14), autonomy scale $0.91(S E M=0.20)$, intimacy scale $0.92(\mathrm{SEM}=0.21)$ reliability and autonomy scale in these studies 0.93 (SEM=0.20), intimacy scale 0.93 (SEM=0.21)] tool for measuring perceptions of health in the family of origin in terms of relational intimacy and autonomy. The accuracy of the factor method warrants caution. The theoretical model was not confirmed 
Table 1. Differences in the frequency of conflict resolution strategies by all partners in engaged couples

\begin{tabular}{lccccc}
\hline $\begin{array}{l}\text { Type of conflict } \\
\text { resolution strategies }\end{array}$ & Male & Female & Male & Female & $\mathrm{t}$ \\
\hline Loyalty & 4.36 & 3.80 & 0.58 & 0.55 & $5.27^{* * *}$ \\
Exit & 2.10 & 2.63 & 0.50 & 0.67 & $-4.74^{* * *}$ \\
Neglect & 2.18 & 2.89 & 0.62 & 1.14 & $-4.12^{* * *}$ \\
\hline
\end{tabular}

${ }^{* * *} \mathrm{p}<0.001$, Student's t-test

by empirical verification. The test results are inconclusive (Mazer, Mangrum, Hovestadt, \& Brashear, 1990; Ryan, Kawash, Fine, \& Powel, 1994; Schouten, 1996). Despite this, the value of the results in terms of accuracy and reliability allow the method to be applied in group studies. It should be noted, however, that information about the high utility of the clinical method is also found in literature (Mazer et al., 1990; Hovestadt, 2000).

\section{Results}

Men and women (preparing for marriage) differ in the intensity of three out of the four conflict resolution strategies, with a similar profile of these strategies. Detailed results are presented in Table 1.

The differences pertain to the strategies of loyalty, exit and neglect on statistically significant levels. There was no such difference recorded for the dialogue strategy.

Men (more often than women) avoid open confrontation in the hope that the problem will resolve itself. Women often apply destructive strategies - both leading to escalation of the conflict and withdrawing from efforts to resolve the problem, feeding the belief that it is unsolvable. Gender therefore constitutes a factor differentiating the conflict resolution strategies, which of course was to be expected, if only because of differences in communication styles (Cross \& Markus, 2002 , p. 69-70). Then the intensities of certain relational patterns in the families of origin of men and women were compared. Gender constitutes a differential variable only in intergenerational intimacy patterns. Women declare an average of greater intimacy and satisfaction with relationships with parents $(M=3.99$, $S=0.11)$ than men $(M=3.70, S D=0.08)$. The difference is statistically significant $(t=-2.15, \mathrm{p}<0.05)$.

As expected, gender does not constitute a variable differentiating perceptions of relational patterns. The correlation between relational patterns and conflict resolution strategies was examined separately for men and women at a later stage. 
Table 2. Values of correlation coefficients for conflict resolution strategies and relational patterns in the women's group

\begin{tabular}{lcccc}
\hline \multirow{2}{*}{ Relational Patterns } & \multicolumn{3}{c}{ Conflict Resolution Strategies } \\
& Dialogue & Loyalty & Exit & Neglect \\
\hline $\begin{array}{l}\text { Partner intimacy } \\
\text { Partner fusion / individuation }\end{array}$ & $0.376^{* *}$ & $-0.317^{*}$ & \\
Intergenerational intimacy & & $0.337^{*}$ & \\
Intergenerational fusion / individuation & $0.298^{*}$ & & $-0.277^{*}$ & \\
Intergenerational intimidation & & & $-0.304^{*}$ & \\
Personal authority in the family system & $0.322^{*}$ & & & $-0.302^{*}$ \\
Personal responsibility & $0.304^{*}$ & & $-0.447^{* *}$ & \\
Respect for others & & $0.302^{*}$ & & \\
Openness to others & & & & $-0.307^{*}$ \\
Autonomy & $0.289^{*}$ & & $-0.283^{*}$ & $-0.284^{*}$ \\
Range of emotions & $0.270^{*}$ & $0.346^{* *}$ & $-0.286^{*}$ & $-0.292^{*}$ \\
Mood and tone & $0.321^{*}$ & $0.274^{*}$ & & $-0.290^{*}$ \\
Conflict resolution & & $0.331^{*}$ & & \\
Empathy & & $0.335^{*}$ & & \\
Trust & & & \\
Intimacy & $0.288^{*}$ & & & $-0.264^{*}$ \\
\hline
\end{tabular}

${ }^{*} \mathrm{p}<0.05 ;{ }^{* *} \mathrm{p}<0.01 ;{ }^{* * *} \mathrm{p}<0.001$

Table 3. Values of correlation coefficients for conflict resolution strategies and relational patterns in the men's group

\begin{tabular}{lcccc}
\hline \multirow{2}{*}{ Relational Patterns } & \multicolumn{3}{c}{ Conflict Resolution Strategies } \\
& Dialogue & Loyalty & Exit & Neglect \\
\hline Partner intimacy & $0.485\left(^{* *}\right)$ & $0.283\left(^{*}\right)$ & $-0.507\left(^{* *}\right)$ & $-0.410\left(^{* *}\right)$ \\
Partner fusion / individuation & $0.264\left(^{*}\right)$ & & & $-0.326\left(^{*}\right)$ \\
Intergenerational triangulation & $-0.283\left(^{*}\right)$ & & & \\
Intergenerational intimidation & $0.361\left(^{* *}\right)$ & & & $-0.531\left(^{* * *}\right)$ \\
Mood and tone & & $0.269\left(^{*}\right)$ & & \\
\hline
\end{tabular}

${ }^{*} \mathrm{p}<0.05 ;{ }^{* *} \mathrm{p}<0.01 ;{ }^{* * *} \mathrm{p}<0.001$

When comparing the data in Tables 2 and 3, note the following regularities:

1. The network of correlational relationships between conflict resolution strategies and relational patterns in the women's group (28 correlates, all presented in Table 2 ) is more extensive than in the men's group (10 correlates, all presented in Table 3). 
2. For the women, only slightly more than $7 \%$ correlation describes the relationship of conflict resolution strategies (and these are solely constructive strategies) to the relational patterns with the partner, over $92 \%$ are associations with the patterns describing the relationship with parents. For men it is $60 \%$ and $40 \%$, respectively. For men, all the strategies are associated with partner relationship patterns.

3. Inasmuch as destructive strategies (exit and neglect) among women are exclusively associated with relational patterns in the family of origin, exit strategies are strongly associated exclusively with low levels of partnership intimacy among men.

4. Constructive conflict resolution strategies among women are more widely associated with greater intensity of the various aspects of intimacy in the family, whereas destructive strategies are associated with lower levels of autonomy (in its various aspects) and distinguishment from the family of origin. In the men's group, intimacy and autonomy in the family of origin are not essentially related to the conflict resolution strategies. The only exception is the correlation of the loyalty strategy with the level of positive and friendly atmosphere in the family of origin (which partially describes the level of intimacy).

5. Among the men, significant correlational relationships between patterns in the family of origin emerged: intergenerational triangulation (this turned out to be statistically insignificant for women) and intergenerational intimidation.

\section{Overview and discussion of results}

Hypothesis 1. It was assumed that men and women differ in the scope of conflict resolution strategies - women prefer active conflict resolution strategies (dialogue, exit), while men prefer passive strategies (loyalty, neglect).

The results obtained indicate that men and women differ significantly within the confines of conflict resolution strategies. However, the nature of these differences does not fully coincide with the assumption. Women, according to the proposed hypothesis, declare the employment of exit strategies more often than men, while men declare loyalty strategies. Contrary to the assumptions, women often declared the employment of neglect strategies, and men and women's dialogue strategies did not significantly differ in intensity.

The assumed difference in terms of passiveness/activeness, therefore, was not confirmed by the results of this study. An interesting outcome was the application of destructive strategies by women, especially as (according to stereotypes and research results) higher levels of aggression are often attributed to men (Hyde \& Frost, 2002, p. 31-33). A rivalry-based communication style and aspiring to gain an advantage over others is also attributed to men (Cross \& Markus, 2002; Hyde \& Frost, 2002). 
The dialogue strategy, applied by men and women with a similar intensity, may have different meanings depending on gender. For women, this strategy may take the form of more direct communication, more openness and a stronger need to share thoughts and feelings: the same reasons they first brought attention to the existence of the problem or difficulties. Men, on the other hand, may be more inclined to effectively resolve the problem, owing to a greater ability to separate emotion from the cognitive sphere, concentration and a task approach to the problem (Blum, 2000; Brannon, 2002): the same reasons that the decision about the ultimately adopted solution often belongs to men (Bell, Cowan, \& Cowan, 1995).

Women place higher demands on men and formulate them with greater intensity: their commitment to the relationship is stronger (Kenrick, Sadalla, Groth, \& Trost, 1990). Likewise, a stronger tendency to disclose emotions, views and insights, directness of communication and openness among women, as mentioned in the dialogue strategy, also applies to critical and negative aspects. The greater emotional distance to problems, and the more task-focused and problem-concentrated approach to the problem by men may also cause them to obtain lower scores in this scale.

An interesting result is the assignment of more likely exit strategies to women. It may be supposed that with the higher expectations formulated by women, an inability to meet the requirements or expectations can lead to withdrawal from the relationship. This is all the more since the reactions of women in conflict situations may not only be more emotional, but the negative affect may also last longer. At its core the neglect strategy may lack faith in the possibility to change an unfavorable, conflict situation. It does seem, however, that the behavior of women in the field of conflict resolution strategies could serve a different function. It may be a form of punishing a partner through the use of indirect forms of aggression - ignoring the partner, indifference, offending them. Such behavior may also constitute a form of attention drawing and exertion of influence on the partner, when previous attempts have not yielded results. This perspective seems all the more likely in the light of the fact that emotional contact and intimacy are particularly important to women.

Higher levels of intensity of loyalty strategies in men remained in line with the basis of winning over emotional attitudes in conflict situations mentioned earlier. Loyalty is a strategy which minimizes the risk of escalation of the conflict in the belief that the problem will resolve itself - this would be consistent with the results of studies in which men are unlikely to bring attention to the problem. Explanations of this result may also explore the different ways men and women perceive things and think. Men pay less attention (than women) to information related to others and relationships (Cross \& Markus, 2002, p. 67-68). For this reason, men may pay less attention to their partner's behaviors indicating that something negative is happening in the relationship, ascribing less importance to this behavior. 
Hypothesis 2. Men and women do not differ in relational patterns within the family of origin.

Gender does not constitute a differential variable of perception of relational patterns (relatively permanent emotional reference systems between people in a family) in the family of origin. The exception is intergenerational intimacy, whose intensity is significantly higher among women. These results are therefore in accordance with expectations and the studies mentioned earlier (Maccoby \& Jacklin, 1974; Margonin \& Patterson, 1975; Lytton \& Romney, 1991), as relatational patterns are shaped in the family system, which influences a child regardless of gender. The results obtained would confirm the similarity of socialization in this respect, though it seems that different significance is given to the same relational pattern depending on gender. A similar intensity of relational patterns will have different meanings for boys and girls from a social roles perspective.

Hypothesis 3. It was predicted that a similar perception of the intensity of relational patterns will create other correlative relationships with conflict resolution strategies, depending on gender, and this has been confirmed. On the basis of the results obtained, it seems that relational patterns in the family of origin may have greater importance for women's conflict resolution strategies with their partners. In the case of men, however, relational patterns with the partner seem to play a greater role - particularly the level of intimacy between partners.

Hypothesis 3a. It was assumed that constructive conflict resolution strategies among women coincided with higher levels of intergenerational and partnership intimacy and personal authority, whereas destructive strategies coincided with low levels of intergenerational and partnership intimacy and personal authority. Because the identity of women is defined to a greater degree by relationships with others, appropriate individuation (particularly its consequences in the form of autonomy and intimacy) is of greater importance for constructive conflict resolution strategies. These patterns allow women to define themselves in relationships with others, and define their own needs and goals. A greater intensity of these patterns also allows for the conscious formulation of their own expectations. Here the sense of security provided by the family of origin - shaping the space of intimacy, support while respecting intimacy, and independence - is also conducive to constructive conflict resolution strategies. It seems to be especially significant that insecure people in close relationships will strive to attain a sense of personal security more than looking after the partner relationship. Freedom from focusing exclusively on one's self is conducive to greater distance in relation to one's self and experienced situations, leaving more energy for "seeing" the partner, bringing one's self to be understanding and seeking mutual solutions to conflict situations. Appropriate individuation, higher levels of personal authority in the family system, and autonomy (especially in the dimension of personal responsibility) are conducive to active dialogue. It seems that the pattern 
of personal authority may constitute the "key" to elucidating the aforementioned relationships.

Personal authority in the family system means the position an individual assumes in the family. Appropriate autonomy and intimacy lies at the base of personal authority. Low levels of autonomy and personal authority may result in the "battlefield for sovereignty" being shifted onto the area of the relationship. By the same token, a couple's conflict situation may become an occasion to fight themselves out some autonomy, rather than building up the relationship. Autonomy and personal authority are of particular significance in the case of women. Low intensity of these patterns may result in temporary, excessive conciliation and concession in a partner relationship, which according to the test results of Gotmann and Levenson (Gottman, 1991; Levenson, Carstensen, \& Gottman, 1994) increases the likelihood of a breakup. It seems all the more significant that according to research studies (Duck, 1991, cited also: Brannon, 2002, p. 311), 80\% of breakups are initiated by women.

Hypothesis $3 \mathrm{~b}$ supposed that constructive strategies among men were primarily associated with higher levels of autonomy, and that lower levels of autonomy were conducive to destructive strategies.

This hypothesis was directly confirmed only in the scope of autonomy in partner relationships. Higher levels of individuation favored dialogue strategies, while lower levels favored withdrawal. A direct link between conflict resolution strategies and autonomy in the family of origin was not established, however. It seems that what happens between partners (for men's conflict resolution strategies) is more important than relations in the family of origin - as here more can be indirectly inferred about the relationship. Higher levels of triangulation indirectly indicate weaker self-distinguishment from the family of origin. The family of origin "does not allow" one of its members to break away, pulling him into conflict. Greater involvement of parents in conflicts is associated with weaker constructive participation in seeking resolutions to conflicts in one's own relationship. This correlation seems to simultaneously indicate two aspects: a low level of autonomy in the family of origin and parent's involvement in maintaining tension on a lower level. Being "the third person" is an exhausting, emotionally burdensome task and is strongly associated with the dyad. This may make both "retreating" to the relationship (higher levels of intergenerational triangulation are associated with lower levels of partnership intimacy among men) and participating in seeking constructive resolutions to conflicts in their own relationships difficult.

Another pattern which may indirectly indicate an association between the conflict resolution strategy and the level of autonomy in the family of origin is intergenerational intimidation. A stronger belief in one's own independence and ability to manage without the help of others favors the neglect strategy. Men of low confidence in their own adequacy are more inclined to actively seek conflict resolutions. Belief in one's own helplessness without the support of the family 
system inclines men in some ways to fight for support, mobilizing them to actively seek constructive solutions, while belief in one's own strength is more conducive to leaving the relationship. This seems interesting, as withdrawal strategies result from a belief in one's own helplessness and lack of influence on the relationship in the dyad. Perhaps a sense of weakness releases a reaction of confirming one's own identity through the task, while men convinced of their own strength do not need this kind of confirmation, the same reason that conflict situations do not constitute an occasion for them to strengthen their "I".

\section{Conclusions}

Searching for and more precisely defining the factors involved in elucidating conflict resolution strategies seems to be essential in terms of widening the understanding of the difficulties and complexity of this process. This could indicate that these factors cause the learning of interpersonal communication principles in intimate relationships to not yield the intended results. Upon undertaking this research, it was expected that men and women would not differ in their perceptions of relational patterns, whereas differences would be manifested in the kinds of connections between these patterns and conflict resolution strategies.

The results presented here confirm the hypothesis that similar relational patterns in the family of origin may have different importance for conflict resolution strategies, depending on a child's gender, while these connections are wider among women (especially with intimacy, autonomy and personal authority in the family system). However, conflict resolution strategies among men are more strongly related to relational patterns in the partner relationship (partner intimacy and individuation are of special importance). At a later stage of research, it may be worth verifying in what ways conflict resolution strategies change in different stages of relationships and what importance relational patterns have for these changes. Conducting such an analysis could indicate which of the relational patterns are conducive to changes in the direction of constructive conflict resolution strategies.

\section{References}

Bell, F.L., Cowan, P., \& Cowan, C.P. (1995). Who's got power? Gender differences in partners' perceptions of influence during marital problem-solving discussion. Family Process, 34, 303-321.

Blum, D. (2000). Mózg i płeć [Sex on the brain]. Warszawa: Prószyński i S-ka.

Bowen, M. (1976). Theory in the practice of psychotherapy. In P.J. Guerin Jr. (Eds.), Family therapy: Theory and practice (pp. 42-90). New York: Gardner Press. Bowen, M. (1978). Family therapy in clinical practice. New York: Jason Aronson. Brannon, L. (2002). Psychologia rodzaju [Gender: Psychological perspectives]. Gdańsk: GWP. 
Cross, S.E. \& Markus, H.R. (2002). Płeć w myśleniu przekonaniach i działaniu: podejście poznawcze [Gender in thought, belief, and action: a cognitive approach]. In B. Wojciszke (Eds.), Kobiety i mężczyźni: odmienne spojrzenia na różnice [Women and men: Different perspectives on differences] (pp. 48-80). Gdańsk: GWP.

Darling, N., Cohan, C.L., Burns, A., \& Thompson, L. (2008). Within-family conflict behaviors as predictors of conflict in adolescent romantic relations. Fournal of Adolescence, 31 (6), 671-690.

Edwards, R., Allen, M.W., \& Hayhoe, C. R. (2007). Financial attitudes and family communication about students' finances: The role of sex differences. Communication Reports, 20 (2), 90-100.

Fajkowska-Stanik, M. (1999a). Polska adaptacja Kwestionariusza Autorytetu Osobistego w Systemie Rodzinnym Williamsona, Braya, Harveya, Malone'a [Polish adaptation of the Personal Authority in Williamson, Bray, Harvey, and Malone's Personal Authority in Family Systems Questionnaire]. Czasopismo Psychologiczne, 5 (3), 257-268.

Fajkowska-Stanik, M. (1999b). Polska adaptacja skali Rodziny Pochodzenia Hovestadta, Andersona, Piercy'ego, Cochrana i Fine'a [Polish adaptation of Hovestadt, Anderson, Piercy, Cochran, and Fine's Family of Origin Scale]. Przeglad Psychologiczny, 42 (3), 51-67.

Fajkowska-Stanik, M. (2001). Transseksualizm i rodzina. Przekaz pokoleniowy wzorów relacyjnych $w$ rodzinach transseksualnych kobiet [Transsexualism and family: Intergenerational transmission of relational patterns in transsexual women's families]. Warszawa: Wydawnictwo Instytutu Psychologii PAN.

Gottman, J.M. (1991). Finding the roots of children's problems with other children. Journal of social and Personal Relationships, 8 (3), 441-448.

Hoffman, L. (1981). Foundations of family therapy: A conceptual framework for systems change. New York: Basic Books.

Hovestadt, A.J. (2000). Unresolved coupe conflict: Clinical use of the Family of Origin Scale. In R.E. Watts (Eds.), Techniques in marriage and family counseling. Vol. 1 (pp. 75-80). Alexandria, VA: American Counseling Association.

Hyde, J.S. \& Frost, L.A. (2002). Metaanalizy w psychologii kobiety [Meta-analysis in the psychology of women]. In B. Wojciszke (Eds.), Kobiety i mężczyźni: odmienne spojrzenia na różnice [Women and men: Different perspectives on differences] (pp. 15-47). Gdańsk: GWP.

Kenrick, D.T., Sadalla, E.K., Groth, G., \& Trost, M.R., (1990). Evolution, traits, and the stages of human courtship: qualifying the parental investment model. fournal of Personality, 58, 98-116.

Kriegelewicz, O. (2003). Kwestionariusz do badania strategii rozwiązywania konfliktów w parze małżeńskiej [A Questionnaire for research on married couples' conflict resolution strategies]. Nowiny Psychologiczne, 4, 15-31.

Levenson, R.W., Carstensen, L.L., \& Gottman, J.M. (1994). Influence of age and 
gender on affect, physiology and their interrelations: A study of long-term marriages. fournal of Personality and Social Psychology, 67 (1), 56-68.

Lytton, H., \& Romney, D.M. (1991). Parents' differentia socialization of boys and girls: A meta-analysis. Psychological Bulletin, 109, 267-296.

Maccoby, E.E. \& Jacklin, C.N. (1974). The psychology of sex differences. Stanford: Stanford University Press.

Margolin, G. \& Petterson, G.R. (1975). Differential consequences provided by mothers and fathers for their sons and daughters. Developmental Psychology, 11, 537-538.

Mazer, G.E., Mangrum, O.L., Hovestadt, A.J., \& Brashear, R.L. (1990). Further validation of the Family of Origin Scale: a factor analysis. Fournal of Marital and Family Therapy, 16 (4), 423-426.

Minuchin, S. (1974). Family and family therapy. Cambridge: Harvard University Press.

Raush, H.L., Barry, W.A., Hertel, R.K., \& Swain, M.A (1974). Communication, conflict and marriage. Oxford, England: Jossey-Bass Publication.

Reese-Weber, M. \& Bartle-Haring, S. (1998). Conflict resolution styles in family subsystems and adolescent romantic relationships. Fournal of Youth and Adolescence, 27(6), 735-752.

Reese-Weber, M. \& Kahn, J.H. (2005). Familial predictors of sibling and romanticpartner conflict resolution: comparing late adolescents from intact and divorced families. Journal of Adolescence, 28 (4), 479-493.

Rusbult, C.E., Johnson, D.J., \& Morrow, G.D.(1986). Determinants and consequences of exit, voice, loyalty, and neglect: responses to dissatisfaction in adult romantic involvements. Human Relations, 39 (1), 45-63.

Rusbult, C.E., Zembrodt, I.M., \& Gunn L.K. (1982). Exit, voice, loyalty, and neglect: responses to dissatisfaction in romantic involvements. Fournal of Personality and Social Psychology, 43, 1230-1242.

Ryan, B.A., Kawash, G.F., Fine, M., \& Powel, B. (1994). The Family of Origin Scale: a construct validation study. Contemporary Family Therapy: An International fournal, 16 (2), 145-159.

Szarf, M. (1989). Trójkąty emocjonalne [Emotional triangles]. In R. Praszkier (Ed.), Mity i rzeczywistość terapii rodzinnej [Myth and reality of family therapy]. Vol. 3 (pp. 54-56). Warszawa: Synapsis.

Schouten, P. (1996). Researchers discover what they already knew about validity: the case of the Family of Origin Scale. Contemporary Family Therapy: An International fournal, 18 (2), 315-323.

Simon, V.A. \& Furman, W. (2010). Interparental conflict and adolescents' romantic relationship conflict. Journal of Research on Adolescence, 20 (1), 188-209.

Stierlin, H., Rücker-Embdon, I., Wethel, N., \& Wirsching, M. (1980). The first interview with the family. New York: Brunner/Mazel. 
